\title{
Assessment of Potential Risk in Soil and Early Warning Analysis in Four Counties, Northeast China
}

\author{
Lingling Sang ${ }^{1}$, Chao Zhang ${ }^{1, *}$, Jianyu Yang ${ }^{1}$, Dehai Zhu ${ }^{1}$, and Wenju Yun ${ }^{2}$ \\ ${ }^{1}$ College of Information and Electrical Engineering, \\ China Agricultural University, Beijing, 100083, P.R. China \\ zhangchaobj@cau .edu.cn \\ ${ }^{2}$ Land Consolidation and Rehabilitation Center, \\ Ministry of Land and Resources, Beijing 100035, P.R. China
}

\begin{abstract}
Heavy metal pollutions in the soil have been an important content of its quality. The objectives of this study were to evaluate the potential risk of heavy metals and early warning analysis of agricultural soil in four counties, Northeast China. One method based on toxicity coefficients was applied to assess the potential risk of these heavy metals in soil. The results showed that average content of $\mathrm{Cu}, \mathrm{Pb}, \mathrm{Zn}, \mathrm{Cd}, \mathrm{As}, \mathrm{Ni}, \mathrm{Hg}$ and $\mathrm{Cr}$ in agricultural soil was lower than the first level standard of agricultural soil, and Cd led to risk was the most important factor, which $0.21 \%$ of the area was in the state of potential risk of elements $\mathrm{Cd}$. And other heavy metals were not harmful to the environment, which potential risk of harm in descending order is $\mathrm{E}(\mathrm{Cd})>\mathrm{E}(\mathrm{Hg})>\mathrm{E}(\mathrm{As})>\mathrm{E}$ $(\mathrm{Ni})>\mathrm{E}(\mathrm{Cu})>\mathrm{E}(\mathrm{Pb})>\mathrm{E}(\mathrm{Cr})>\mathrm{E}(\mathrm{Zn})$; The other method is that the Cd pollutants can be calculated by the atmospheric dry and wet deposition, the irrigation water, the chemical fertilizer and the crops. There was a point on the assumption that the pollution caused by the atmospheric dry and wet deposition was worse than the pollution from irrigation water and chemical fertilizer. It is concluded that heavy metal pollution of $\mathrm{Cd}$ in the southeast of the study area will be getting worse within the next few decades by forecast warning analysis. Overall, some part of study area is in the state of potential risk and the Cd of soil is a major factor to control the retention of the heavy metals in the soil. According to analysis of their characteristics and the level of potential risk, there will not be great impact on quality by developing appropriate control measures timely.
\end{abstract}

Keywords: agricultural soil, heavy metal, potential risk, early warning.

\section{Introduction}

The quality of the field is not only the comprehensive measurement for the quality of the soil, environment and health of the overall field, but also the main embodiment for the ability of maintaining the productive power, fighting against natural calamities, and hazard-free treatment of the agricultural products and the high nutrition and

\footnotetext{
* Corresponding author.
} 
quality[1]. In recent years, the evaluation for the agricultural products usually focuses on the productivity and the effectiveness, among which the classification of the agricultural field and the earth chemical evaluation for the quality of the soil are considered as two important branch of the soil quality evaluation $[2,3]$. Those two works undertake scientific evaluation to the quality of the soil as well as the eco- environment from different perspective and conform to each other in terms of the rational application of the soil. However, the evaluation upon the agriculture focuses on the effects of the quality of agricultural field and considers the earth chemical evaluation for the quality of the soil as part of the standard for the evaluation of the environmentfriendly and healthy elements [4].

In recent years, the intensified industrialization and urbanization as well as the effects of human activity lead to many eco environmental problems, among which the heavy metal pollution of the agriculture field has aroused extensive concern of the overseas and domestic scholars [5]. As the important earth resource, agriculture field has shift from the state of insufficient quantity to the state of premium insufficient quantity, which in essence implies important environment pollution and the food safety and affects negatively upon the human health and environmental safety. Therefore, it is of high significance to undertake risk evaluation to the heavy metal pollution of the soil and the early warning analysis [6].

Taking some counties in Northeast China as the sample region, based on the data of heavy metals, the paper analyzed its potential sources of heavy metals and assessed the potential risks of heavy metals. According to early warning after the study, the protective measures are put forward, providing the scientific suggestion for the farmland protection and the security of land resource.

\section{Data and Methods}

\subsection{Study Area and Data}

The southwest of Songnen Plain, which is also the western region of Jilin Province, belongs to the sub humid and sub arid continental and seasonal climate zone with obvious changes of the weather in the year. The annual rainfall is about $400 \mathrm{~mm}$, which is 3.5-4.7 times of the evaporation capacity. Due to the difference of the agricultural climate condition and the earth eco condition, it forms the combined agricultural production state of both the typical agricultural region and the ecotone between agriculture and animal husbandry. The soil types are mainly composed of meadow soil, black earth, saline-alkali soil, and aeolian sandy soil. The loose structure of the soil deduces the capability of preserving moisture and fertility, so that the natural structure and the fertility would be damaged by the drought and flood. Because of human beings' interference, the quality of the soil decreases by a large margin. It is now becoming the potential sand resource for the sandy soil. While the accumulated substance in the plain is sticky and heavy with low penetration power and developing water net so that the water cannot flow out and the soluble salt cannot be drain out, and due to the evaporation, the soil is easy to undertake salinization and 
desertification. Because of the long term overlook of the vulnerably field as well as the long-term and large scale agricultural development, the eco environment of this region is deteriorated, the agricultural and economic development is relatively slow.

This research applies BJZ 54 and Gauss-Kruger Projection to pasteurize the blank miles grid, so that the data of the investment sample could be integrated with the attributes of the blank miles grid and construct the foundation of the research work. The main resource of the data derives from the basic material for the chemical evaluation of the earth quality provided by the Ministry of Land and Resources. In accordance with the multi target earth chemical investigation standard, we station according to the earth chemical sampling method. With the facilitation of the fieldwork illustration of 1:50 000 topographic map, we undertake the investigation on the state-province level. The main investigation focuses on 50 elements including the soil, ground water, shallow ground water, atmospheric bulk deposition, and crop's grain etc. The intensity of the sample is 1 point $/ \mathrm{km}^{2}$, among which there are 5179 soil data sampling spots. The sampling station of this time and the sample analysis are completed by China University of Geosciences and Geological Survey Institute of some Province jointly.

\subsection{Potential Risk Assessment}

The potential risk index method developed by Hakanson [7] was applied in this study. According to this method, the potential risk coefficient ( $E_{r}^{i}$ ) of single element and the potential risk index $(R I)$ of multi-element can be computed via the following equations:

$$
\begin{gathered}
R I=\sum E_{r}^{i} \\
E_{r}^{i}=T_{r}^{i} \times C_{r}^{i} \\
C_{r}^{i}=C_{D}^{i} / C_{F}^{i}
\end{gathered}
$$

In these equations: $C_{r}^{i}=C_{D}^{i} / C_{F}^{i}$ is the accumulating coefficient for the element of " $i$ "and is single heavy metal pollution index; $C_{D}^{i}$ is actual density of heavy metal quality in soil; $C_{F}^{i}$ is background value of heavy metal quality in soil; RI is comprehensive potential risk index of muti-element; $E_{r}^{i}$ is the potential risk index of single element; ${ }^{T}{ }_{r}{ }^{i}$ is the toxicity coefficient for the heavy metals element of "i", reflects its toxicity levels and the sensitivity to harm the human and the ecosystem. The toxicity coefficients for common heavy metals were $\mathrm{Hg}(40)>\mathrm{Cd}$ (30) >As (10) > $\mathrm{Pb}(5)=\mathrm{Ni}(5)=\mathrm{Cu}(5)>\mathrm{Cr}$ (2) $>\mathrm{Zn}$ (1) [7][8]. Table 1 is the Classification standard of potential risk of heavy metals in soil. 
Table 1. Classification standard of potential risk of heavy metals in soil

\begin{tabular}{llll}
\hline \multicolumn{1}{c}{$E_{r}^{i}$} & \multicolumn{1}{c}{ Pollution degree } & \multicolumn{1}{c}{$R I$} & \multicolumn{1}{c}{ Pollution degree } \\
\hline$E_{r}^{i}<30$ & Low potential risk & $R I<135$ & Low potential risk \\
$30 \leq E_{r}^{i}<60$ & Moderate potential risk & $135 \leq R I<265$ & Moderate potential risk \\
$60 \leq E_{r}^{i}<120$ & Considerable potential risk & $265 \leq R I<525$ & Considerable potential risk \\
$120 \leq E_{r}^{i}<240$ & Very high potential risk & $R I \geq 525$ & Very high potential risk \\
$E_{r}^{i} \geq 240$ & Serious potential risk & & \\
\hline
\end{tabular}

\subsection{Early Warning Analysis}

In this paper, the research on the atmospheric dry and wet deposition, the irrigation water and the chemical fertilizer in the $\mathrm{Cd}$ were analyzed. Input pathway of $\mathrm{Cd}$ in soil is mainly from the atmospheric dry and wet deposition, the irrigation water and the chemical fertilizer, output pathway of $\mathrm{Cd}$ in soil is mainly from the crops $[9,11]$. According to the concept of potential risks, the total Contents of the Cd pollutants can be calculated by the atmospheric dry and wet deposition, the irrigation water, the chemical fertilizer and the crops via the following equations:

$$
\begin{gathered}
D I=(D+I+F)-O P \\
M=D I_{m} \times n+M_{0}
\end{gathered}
$$

In these equations: $D I$ is the total input of heavy metal in soil, and the unit is $\mathrm{g} /\left(\mathrm{hm}^{2} \cdot \mathrm{a}\right)$; $D, I, F$ are respectively input of heavy metal in soil by the atmospheric dry and wet deposition, the irrigation water, and the unit is $\mathrm{g} /\left(\mathrm{hm}^{2} \cdot \mathrm{a}\right) ; O P$ is the total output of heavy metal in soil for the element of " $i$ ", and the unit is $\mathrm{g} /\left(\mathrm{hm}^{2} \cdot \mathrm{a}\right) ; M$ is the total content of heavy metal in soil for the element of " $i$ " for several years $(n)$ later, and the unit is $\mathrm{mg} \cdot \mathrm{kg}^{-1} ; M_{0}$ is the current input of heavy metal in soil, and the unit is $\mathrm{mg} \cdot \mathrm{kg}^{-1}$.

\section{Results and Discussion}

\subsection{Characteristic Analysis of the Content of Heavy Metal in Farmland Soil}

The analysis results of heavy metal contents of farmland soil in four counties of Northeast China are listed in Figure 1. Statistical analysis of the heavy metals of $\mathrm{Cd}$, $\mathrm{Hg}, \mathrm{As}, \mathrm{Cu}, \mathrm{Pb}, \mathrm{Cr}, \mathrm{Zn}$ and $\mathrm{Ni}$ in farmland soil has proved to be normal distribution. In this paper, arithmetic mean value and median value were used to describe the contents of heavy metals in the soil. Compared with Environmental Quality Standard for Soils in China (GB 15618-1995) [10], average content of $\mathrm{Cu}, \mathrm{Pb}, \mathrm{Zn}, \mathrm{Cd}, \mathrm{As}, \mathrm{Ni}, \mathrm{Hg}$ and $\mathrm{Cr}$ in agricultural soil was lower than the national first class standard of agricultural soil, and the heavy metal contents in the soil was in the natural background level basically in study area. In addition to $\mathrm{Cd}$, the maximum value of the content of each element was lower than the national secondary standard. 

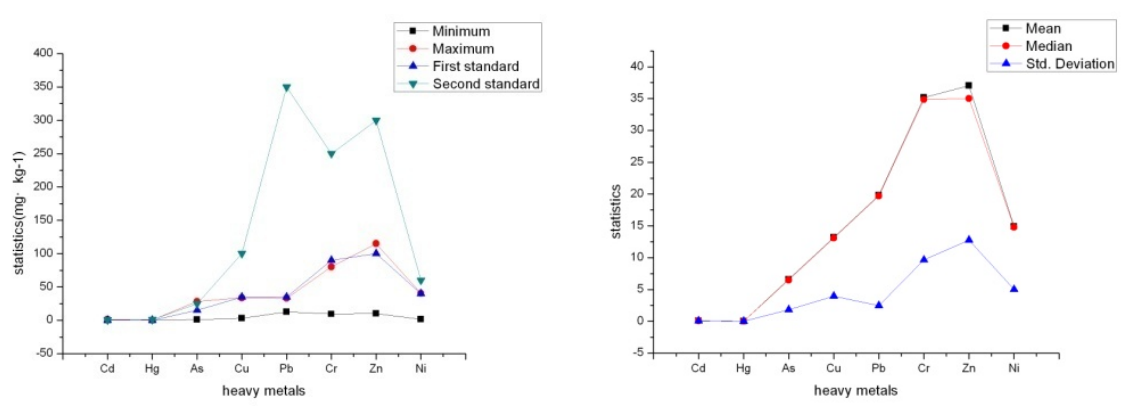

Fig. 1. Statistics of heavy metal concentrations in soil of study area

Based on the monitoring data of soil quality of study area, a quantitative analysis of farmland soil is conducted by applying the method of single and composite pollution exponent Indexes. The analysis results showed that there were 11 units in the soil samples pollution of heavy metal $\mathrm{Cd}$ and one unit in the soil samples pollution of heavy metal As. Other units in the soil samples were almost non-pollution. Three units in soil samples were light pollution (integration pollution index is from 1.0 to 2.0), and ten units in soil samples were to be at the alert posture (integration pollution index is from 0.7 to 1.0 ). Other units' synthesis pollution index was smaller than 0.7 , belongs to the security rank (integration pollution index is lower than 0.7 ). $99.79 \%$ of the total land area was at safety level, $0.17 \%$ affected by light pollution and $0.04 \%$ affected by medium pollution.

Several results had been obtained: At the 5179 sampling sites in study area, the heavy metal pollution index descended in the order of $\operatorname{Cd}(2.30)>\operatorname{As}(1.14)>$ $\mathrm{Hg}(0.52)>\mathrm{Cr}(0.46)>\mathrm{Pb}(0.11)$. The contents of heavy metals of $\mathrm{Cd}$ and $\mathrm{As}$ in the soil were higher than the contents of other heavy metals, separately accounts for $0.21 \%$ and $0.02 \%$ in Table 2 . So there should pay attention to the increase of the content of soil $\mathrm{Cd}$ and bring the potential risks.

Table 2. Heavy metal pollution

\begin{tabular}{ccccc}
\hline heavy metal & index(Minimum) & index(Maximum) & index(mean) & Portion (\%) \\
\hline Cd & 0.020 & 2.297 & 0.172 & $0.21 \%$ \\
As & 0.040 & 1.140 & 0.259 & $0.02 \%$ \\
\hline
\end{tabular}

\subsection{Single and Comprehensive Potential Risk Assessment of Heavy Metal in Soil}

Refer to the Hakanson assessment method, heavy metal's potential risk index of single element in soil $\left(E_{r}^{i}\right)$ and comprehensive potential risk index of muti-element (RI) were shown in Table 4. From Table 3, the scopes of the potential risk coefficients of 8 kinds of heavy metals are: $E_{r}^{i}(\mathrm{Cd}) 1.8 \sim 206.7, E_{r}^{i} \quad(\mathrm{Hg})$ 1.07 69.6, $E_{r}^{i}$ (As) $0.67 \sim 19, E_{r}^{i} \quad(\mathrm{Cu})$ 0.42 4.81, $E_{r}^{i}(\mathrm{~Pb})$ 1.8 4.73, $E_{r}^{i} \quad(\mathrm{Cr}) 0.21 \sim 1.78 、 E_{r}^{i}$ (Zn) 
$0.1 \sim 1.15, \quad E_{r}^{i} \quad(\mathrm{Ni}) \quad 0.18 \sim 5.08$ 。 From the means of the potential risk coefficients of 8 kinds of heavy metals, the potential risk descended in the order of $\mathrm{E}(\mathrm{Cd})>\mathrm{E}(\mathrm{Hg})$ $>\mathrm{E}(\mathrm{As})>\mathrm{E}(\mathrm{Ni})>\mathrm{E}(\mathrm{Cu})>\mathrm{E}(\mathrm{Pb})>\mathrm{E}(\mathrm{Cr})>\mathrm{E}(\mathrm{Zn})$. According to the calculated accumulating coefficients, $\mathrm{Hg}, \mathrm{As}, \mathrm{Cu}, \mathrm{Pb}, \mathrm{Cr}, \mathrm{Zn}$ and $\mathrm{Ni}$ had not achieved the ecology risk level, $\mathrm{Cd}$ was the most serious polluting element among these heavy metals, and its mean value of $E_{r}^{i}$ was up to 1.8 , and $\mathrm{Cd}$ was the main influencing factor to causes the risk. Some $0.21 \%$ region existed potential risk of $\mathrm{Cd}$ element, and other heavy metals were not harmful to the environment. Therefore $\mathrm{Cd}$ element was the key element to determine to study.

The scope of the potential risk index (RI) of multi-element is 14.87 228.74 in Table 3. According to its frequency distribution in Figure 2, there is no area in the considerable risk and the serious potential risk. $0.06 \%$ of the soil sample points were in a medium risk degree, which the mainly reason was that potential risk coefficient of Cd element was great. The result was shown that agricultural soil in study area would encounter the Moderate risk of Cd element, and 3 soil sampling points $(0.06 \%)$ were above the level of risk.

Table 3. Statistics of potential risk coefficient (E) and potential risk index (RI) of heavy metals in study area

\begin{tabular}{llllllllllll}
\hline & \multicolumn{8}{c}{ potential risk coefficient $E_{r}^{i}$} & \multirow{2}{*}{$\mathrm{RI}$} \\
\cline { 2 - 9 } & $\mathrm{Cd}$ & $\mathrm{Hg}$ & $\mathrm{As}$ & $\mathrm{Cu}$ & $\mathrm{Pb}$ & $\mathrm{Cr}$ & $\mathrm{Zn}$ & $\mathrm{Ni}$ & \\
\hline Minmum & 1.80 & 1.07 & 0.67 & 0.42 & 1.80 & 0.21 & 0.10 & 0.18 & 14.87 \\
Maximum & 206.70 & 69.6 & 19.00 & 4.81 & 4.73 & 1.78 & 1.15 & 5.08 & 228.74 \\
Mean & 14.29 & 5.02 & 4.40 & 1.89 & 2.84 & 0.78 & 0.37 & 1.86 & 31.44 \\
Std.Deviation & 7.51 & 3.34 & 1.21 & 0.57 & 0.35 & 0.21 & 0.13 & 0.63 & 10.02 \\
\hline
\end{tabular}

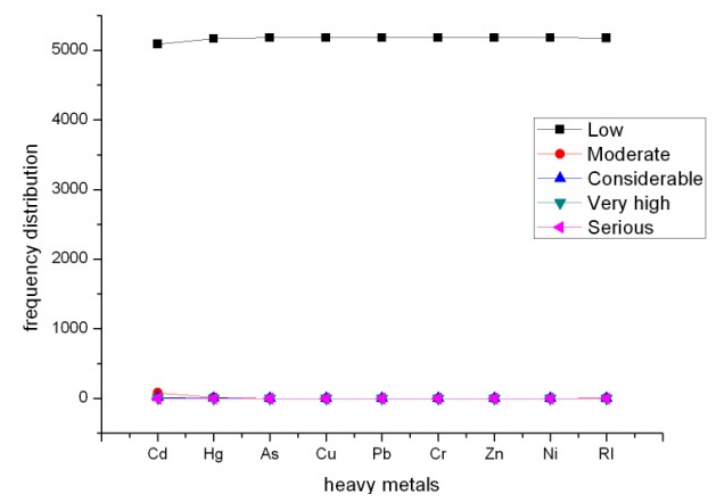

Fig. 2. Frequencies of potential risk coefficient (E) and potential risk index (RI) of heavy metals in study area 


\subsection{Forecast and Early Warning Analysis}

Through the statistical analysis on contents of heavy metals by the atmospheric dry and wet deposition, the ground water and the surface water, the atmospheric dry and wet deposition is the main input way of Cd. Drawing up the maps of $\mathrm{Cd}$ distribution by the spatial interpolation, the results showed that the greatest regional distribution affected by the atmospheric dry and wet deposition were located in the central and southwestern part of Da'an, as well as the northern and southern of Zhanlai. Besides, some areas in the eastern of Qianguo were occupied by acid soils which $\mathrm{Cd}$ pollution needed to pay more attention. This is because the soil $\mathrm{pH}$ is an important factor affecting the content of $\mathrm{Cd}$. The content of $\mathrm{Cd}$ in crops will enrich with the increase of $\mathrm{pH}$ value [11].

Distribution characteristics of $\mathrm{Cd}$ were obtained through connecting the layer properties, re-calculating the content of $\mathrm{Cd}$ by the atmospheric dry and wet deposition and restart interpolation. The potential risks were only considered by input of the dry and wet deposition, and the content of $\mathrm{Cd}$ in soil of agricultural land was increased at an average annual speed of $0.006 \mathrm{mg}$ in Table 4. Evaluations on the potential risk and forecasting were carried by the formula (5), and calculated the content of $\mathrm{Cd}$ in the next 20,50 and 100 years.

Table 4. Annual input of $\mathrm{Cd}$ each grade

\begin{tabular}{c|c}
\hline grade of $C d$ & Annual input $\left(\mathrm{mg} \cdot \mathrm{kg}^{-1}\right)$ \\
\hline 1 & 0.0005 \\
2 & 0.001 \\
3 & 0.0015 \\
4 & 0.0025 \\
5 & 0.004 \\
6 & 0.006 \\
\hline
\end{tabular}

Through computing the content value of $\mathrm{Cd}$ in soil in the next 20,50 and 100 years, and comparing with the standard value of soil environmental quality, the pollution indexes of $\mathrm{Cd}$ element in the next 20,50 and 100 years were calculated and determined whether the risk exists. The areas with heavy warning in the southeast of study area will be lead Cd pollution in the agricultural land area in 20 years in Figure 4(a); the areas with moderate warning in the southeast of study area will be lead $\mathrm{Cd}$ pollution in the agricultural land area in 50 years in Figure 4(b), and the areas with light warning in the southeast of study area will be lead $\mathrm{Cd}$ pollution in the agricultural land area in 100 years in Figure 4(c).

Through the early warning analysis of $\mathrm{Cd}$ element in research area, the area of agricultural land which was polluted by $\mathrm{Cd}$, will be 1634.79 hectares in 20 years; the area of agricultural land which was polluted by $\mathrm{Cd}$ will be 4050.36 hectares in 50 years; the area of agricultural land which was polluted by Cd will be 10355.35 hectares in 100 years. $1.5 \%$ of the total area was with potential risks, and mainly located in the southeastern of study area, where of agricultural land was high-yield and soil type are mainly based on sand. From Figure 3, the area with warning will continue to expand as time goes by, so some preventive measures and early warning suggestions are put forward on the problems. 

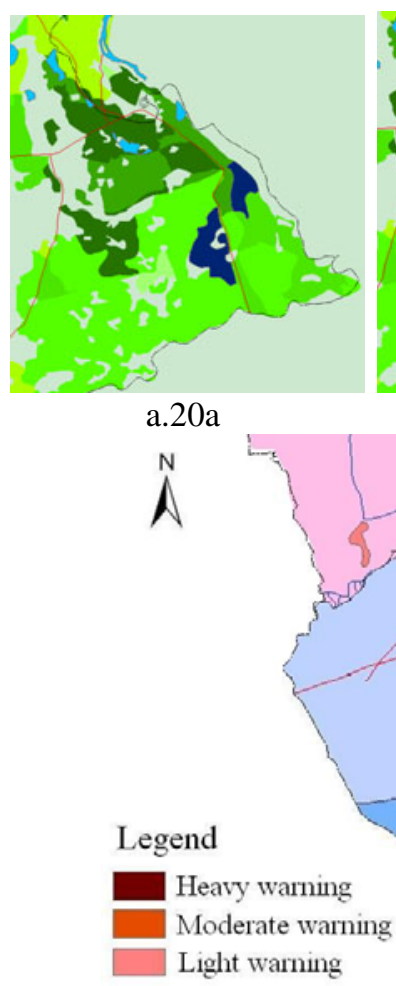

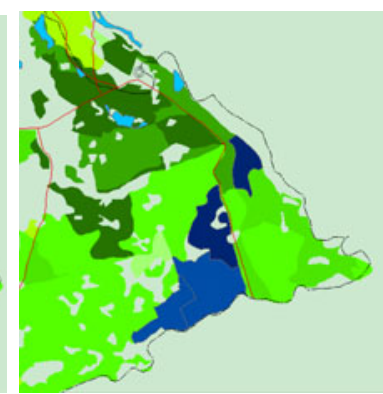

b.50a

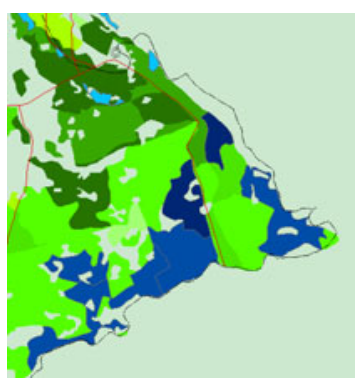

c.100a

Fig. 3. Warning distribution map of heavy metal in soil

\section{Conclusions}

(1) Among the pollution index in the unit soil of the research area, 11 units of $\mathrm{Cd}$ are more than 1, and one of the unit surpasses the As standard, while other elements and unit pollution indexes are all less than 1; In terms of the comprehensive pollution index, there are 3 of the unit belonging to light pollution, 10 of them under the warning state, and other units are blow 0.7, which belong to the safety grade. According to the outcome of the evaluation, $99.79 \%$ of the total research area is labeled as the nonpolluted area during the quality evaluation of the soil environment. Besides, the 11 polluted grid region accounts for $0.21 \%$ of the total research region, among which the number of light polluted area, and 2 middle polluted area.

(2) The damage level of the potential risky heavy metal is as follows: $\mathrm{E}(\mathrm{Cd})>$ $\mathrm{E}(\mathrm{Hg})>\mathrm{E}(\mathrm{As})>\mathrm{E}(\mathrm{Ni})>\mathrm{E}(\mathrm{Cu})>\mathrm{E}(\mathrm{Pb})>\mathrm{E}(\mathrm{Cr})>\mathrm{E}(\mathrm{Zn}) . \mathrm{Hg}$, $\mathrm{As}, \mathrm{Cu}, \mathrm{Pb}, \mathrm{Cr}, \mathrm{Zn}$ and $\mathrm{Ni}$ has not achieved the risky level of the eco pollution, among which $\mathrm{Cd}$ element is the main reason for the influence of the eco system. $0.21 \%$ of the sampling regions are under the potential risk of $\mathrm{Cd}$ pollution, and other heavy metals place little or no damage to the environment. Therefore, $\mathrm{Cd}$ element has been taken as the important research target. 
(3) Through the warning analysis of Cd element in the sampling region, we can draw the conclusion that the Cd pollution would reach $1634.79 \mathrm{hm} 2$ after 20 years, 4 $050.36 \mathrm{hm} 2$ after 50 years and $10355.35 \mathrm{hm} 2$ after 100 years. The total area of the agricultural field under potential risk accounts for $1.5 \%$ of the total area, mainly lying in the southeast region of the research area.

According to the risk evaluation analysis, we could estimate the potential risk confronted by agriculture field, which would set the quantitative basis for not only the administration of the soil environment and the environmental protection, but also the construction of the green agriculture product and the establishment of the heavy metals pollution as well as the proper evaluation to the agriculture field and the environment. Therefore, it is of vital importance to the rational application of the soil resource. Aiming at the outcome of the evaluation, we can draw the conclusion that part of the area is in the potential risk, and we would analyze the reason through further intensification of the sampling station; Because of the lack of investigation data, we only take the atmospheric bulk deposition into consideration in the net quantity of heavy metal $\mathrm{Cd}$ in the potential risk evaluation method. For the lack of the elements like fertilizing, watering and the crops, further study concerning this dynamic mechanism is in need.

Acknowledgements. We are thankful that the study is supported by Geological Survey Institute of some Province, P.R. China and Chinese University of Geosciences (Beijing) which provide the research data for this paper.

\section{References}

1. Gao, X., Ma, R.: Research advances of gradation and evaluation of agricultural land in China. Transactions of the CASE 18(1), 165-168 (2002) (in Chinese)

2. Huang, X., Hu, J., Li, C., et al.: Heavy-metal pollution and potential ecological risk assessment of sediments from Baihua Lake, Guizhou, P.R. China. International Journal of Environmental Health Research 19(6), 405-419 (2009) (in Chinese)

3. Ahnstrom, Z.S., Parker, D.R.: Development and assessment of a sequential extraction procedure for the fractionation of soil cadmium. Soil Sci. Soc. Am. J. 63(6), 1650-1658 (1999)

4. Fernandes, H.M.: Heavy metals distribution in sediments and ecological risk assessment: The role of diagenetic processes in reducing metal toxicity in bottom sediments. Environ. Pollut. 97(3), 317-325 (1997)

5. Donald, L.S.: Toxic metals in the environment: the role of surfaces. Elements 1(4), 193-197 (2005)

6. Casper, S.T., Mehra, A., Farago, M.E., Gill, R.A.: Contamination of surface soils, river water and sediments by trace metals from copper processing industry in the Churnet River Valley, Staffordshire, UK. Environ. Geochem. Health 26(1), 59-67 (2004)

7. Hakanson, L.: An ecological risk index for aquatic pollution control: a sedimentological approach. Water Research 14(8), 975-1001 (1980)

8. Sznopek, J.L., Goonan, T.G.: The materials flow of mercury in the economies of the United States and the world, USA Geological Survey Circular 1197, USA Geological Survey (2000) 
9. USEPA, Review of ecological risk assessment methods EPA/230/1088/041 (1988)

10. GB15618-1995, Environmental Quality Standard for Soils. Standards Press of China, Beijing (1997) (in Chinese)

11. Qifeng, T.: A study of cadmium ecological security forecasting and early warning in agroecosystem of the Chengdu Economic Region. Sichuan. China University of Geosciences (2007) (in Chinese) 